\title{
LA AUTOBIOGRAFÍA: DIALÉCTICA MOCHA Y SUBLIMACIÓN. EN TORNO A LA NARRATIVA DE JORGE BARON BIZA
}

\author{
Autobiography: blunted dialectic and sublimation. About Jorge Baron Biza's \\ narrative
}

\author{
Francisco Tanzi* \\ Universidad Nacional de Rosario \\ franciscotanzi@yahoo.com.ar
}

Palabras clave reconciliación; decadentismo; idealismo

\section{Keywords}

reconciliation; decadentism; idealism

\section{RESUMEN}

La obra de Jorge Baron Biza, El desierto y su semilla, no es sino una novela compuesta de injertos, de vivencias -i. e., de recuerdos en los que predomina más la sensación, tal como argumenta en su programático texto referido al género que practica-. Con ello cobra fuerza la idea de su novela como un montaje de injertos que son presentados en capítulos despojados de toda intriga, de toda épica, de todo desarrollo y finalidad. Allí cada vivencia es un suceso pretérito, cerrado como una mónada, que en juego con los otros promueve un movimiento dialéctico que, aunque pretenda, sabe que no podrá arribar a síntesis alguna, conformándose con el movimiento mismo puesto que al menos en su búsqueda se va reconstruyendo algo de lo que trágicamente se desmoronó (la vida familiar, el rostro de la madre). Aquí, detalles estetizantes de la corrosión también señalan un espíritu decadentista: una retórica del esplendor de la ruina, de la descomposición de la forma. La novela autobiográfica parece procurarse por medio de la escritura un tipo de purga, así se comprende su naturaleza catártica, especie de purificación de la pesada historia familiar por medio de la escritura. Entonces su esperanza conciliatoria, de estéril consecución, opera conjuntamente con un decadentismo que al menos procura una sublimación de la decadencia; la de su mayorazgo.

\section{Abstract}

The work of Jorge Baron Biza, El desierto y su semilla, is a novel just composed of grafts, of experiences -i. e., of memories in which sensation predominates, as Baron Biza himself argues in his programmatic text about the genre he practices-. This enhances the idea about this novel as a montage of grafts that are presented in chapters stripped off all intrigue, all epic, and all development and purpose. There, each experience is a past event, closed as a monad, which, in play with the others, promotes a dialectical movement that despite its attempts, cannot arrive at any synthesis, and thus settling for the movement itself since at least in its search, something that tragically fell apart (family life, the mother's face) is being reconstructed. Here, aestheticizing details of corrosion also point to a decadent spirit: a rhetoric of the splendor of ruin, of the decomposition of form. This autobiographical novel seems to seek a kind of purging or purification of the heavy family history through writing so that its cathartic nature can be understood. Then his conciliatory hope, of sterile achievement, operates together with a decadence that at least seeks a sublimation of decay; that of his legacy. 
1.

"Es de reconciliación de lo que estoy hablando" (Baron Biza, 2013, p. 220). Se sabe que con esa frase culmina la novela autobiográfica de Jorge Baron Biza, El desierto y su semilla, y se sabe que la expresión se reitera, en varias oportunidades, a lo largo de la diégesis de dicha obra. Ocupa ahora entonces preguntarse el porqué de tal anhelo, puesto que es quizá allí donde se podría desplegar alguna clave de lectura de la obra. Tal es, entonces, el disparador del presente artículo.

Se considerarán como punto de partida algunos elementos distintivos de la figura del autobiógrafo. Víctima de una tan trágica como excéntrica historia familiar, en su obra de reconocido carácter autorreferencial ${ }^{1}$ se presentan diversos episodios del drama íntimo, los menos estridentes como así de los más nimios y rutinarios; principalmente la narración se mueve en torno del proceso de reconstrucción del rostro materno tras el atentado perpetrado por el padre en 1964.

Mencioné se mueve puesto que proferir avanza le otorgaría un sentido progresivo que es preferible obviar ya que no se corresponde del todo con la obra. Esta no es sino un conjunto de vivencias compaginadas de un modo un tanto horizontal, no jerarquizado, aunque se mantenga de fondo un cierto ordenamiento cronológico, puesto que narra sucesos que van del año 1964 al año 1978. Los capítulos despojados de todo principio rector recrean los recuerdos que el escritor entresaca de una experiencia vital acontecida a más de quince años. Es precisamente por ello que su novela ofrece esa impresión de estar compuesta por fragmentos; fragmentos que no se despliegan de un modo progresivo o secuencial, sino que son disrupciones que se suceden entre sí formalmente en capítulos. Una analogía que puede presentarse entonces aquí es la del injerto, tal como se desarrollan las curaciones a Eligia -el nombre que otorga el autor a su madre en la novela- en Milán, esto es, con injertos de partes de piel de su propio cuerpo.

Baron Biza elige narrar su drama en una primera persona que logra poner en perspectiva, quizá por la mera distancia cronológica con los hechos, la fatalidad de su historia doméstica. Sin embargo, algo de su propia profesión como crítico de artes visuales se evidencia en las frías descripciones del paisaje facial materno posterior al desastre producido por el vitriolo. Como refiere Nora Avaro en el prólogo a la edición de Eterna Cadencia del año 2013, la de Baron Biza es una "apuesta, artística y vivencial" que "reside en reconstruir (el verbo por excelencia del autor) los avatares de su historia, la suya y la de sus padres" (2013, p. 10).

Es en esa deriva artística en donde irrumpen elementos que ahora señalaré de un modo liminar, pero que se constituirán como claves hermenéuticas: es patente el antes mencionado anhelo reconciliatorio, el que evidenciaría cierta postura idealista, la que se corresponde al mismo tiempo con un canon estético clásico que manifiesta el autor; a su vez, también emerge en la lectura de la obra -sumado a ideas presentes en los textos complementarios del escritor reunidos en el volumen

1. Jorge Baron Biza en una carta al biógrafo de su padre, Christian Ferrer, le confiesa que "la novela -por El desierto y su semilla- es obviamente autobiográfica pero no es confesional” (Avaro, 2013, p. 9). Algo de ello también puede verse ya en el texto de la solapa de su edición de autor de 1998: "Una gran corriente de consuelos afluyó a mí cuando se produjo el primer suicidio en la familia". 
Por dentro todo está permitido-, como un movimiento paralelo al anterior, un matiz que bien puede ser definido como decadentista, y que aporta algo de esa apatía tan característica de su prosa descriptiva, como así también una particular interpretación del tiempo y la historia. Es dentro de una constelación compuesta de estos elementos, más otros derivados de los mismos, y que en primera instancia se revelan ciertamente contradictorios - $\mathrm{O}$ al menos autoexcluyentes-, que se expande la obra de Baron Biza.

2.

Al contemplar el cuerpo de su amante desnuda, Mario -el alter ego del escritor en su obracomprendió que en cualquier dirección que orientara su mirada "cada forma del cuerpo de Dina invitaba a comprender la próxima" (Baron Biza, 2013, p. 196), y allí entendió entonces "que la belleza es totalidad, continuidad que se desarrolla en todas posibilidades" (Baron Biza, 2013, p. 196, la cursiva es mía). En la página siguiente prosigue:

Dina era infragmentable; resultaba inútil tratar de deducir algo de sus labios o de sus músculos abdominales, porque ella era el principio mismo de la unidad. Cada parte de su cuerpo existía tomando en consideración a la que continuaba. (Baron Biza, 2013, p. 197)

En pasajes como estos, Baron Biza manifiesta la carga que tienen sobre él algunos presupuestos de la estética clásica y del pensamiento idealista moderno; ${ }^{2}$ como puede ser por caso, precisamente la noción hegeliana de belleza como sistema y de obra artística como expresión del espíritu, como así también el principio leibniziano de armonía preestablecida. ${ }^{3}$

Dicha influencia de la tradición estética prácticamente nunca es voluntariamente reconocida en El desierto y su semilla, e incluso es negada, ${ }^{4}$ sin embargo es preciso señalar como falaz dicha

2. Cuando hago referencia a la estética clásica considero a la misma no como los contenidos relativos a la estética presentes en los escritos de la tradición clásica griega, sino a la estética en tanto disciplina netamente moderna, iniciada por A. Baumgarten con su obra de 1735 Reflexiones filosóficas acerca de la poesía, y que alcanzó su máxima sistematización en las obras de I. Kant (precisamente en su Crítica del Juicio de 1790) y de G. W. F. Hegel (Lecciones de Estética, publicadas a partir de 1832). Precisamente estos últimos dos autores referidos son, al mismo tiempo, los principales exponentes de la corriente filosófica moderna nominada bajo el rótulo de idealismo alemán.

3. La doctrina leibniziana de la armonía preestablecida afirma que puesto que ninguna mónada (un elemento simple, sin partes, que constituye todo lo existente) puede ejercer ni sufrir acción sobre otra, Dios dispone desde el principio todas sus acciones y reacciones, de modo tal que la acción de cada mónada está programada acorde al de todas las demás del universo. En tal sentido afirmará Leibniz que hay un mundo de criaturas hasta la más pequeña porción de la materia: así cada "porción de la materia puede ser concebida como un jardín lleno de plantas; y como un estanque lleno de peces. Pero cada ramo de la planta, cada miembro del animal, cada gota de sus humores, es, a su vez, un jardín o un estanque semejante". Por lo tanto, entiende Leibniz que "no hay nada de inculto, de estéril o de muerto en el universo, nada de caos, nada de confusiones, sino sólo apariencia de ellos” (Leibniz, 1984, párr. 67 y 69). Es en este sentido entonces que se debe entender que perfección y belleza son continuidad. Así, resulta interesante considerar las pormenorizadas descripciones del rostro estragado de la novela con el argumento del parágrafo 67.

4. En diálogo con el personaje indicado como "un Licenciado", este lo interpela:

“-Hablás como si creyeses en el sujeto, el conocimiento y la ética. ¿No serás un idealista?

- ¡No...! Si de Kant no entiendo nada...

-O peor... ¿No serás un humanista, vos? ¿No? -me miró con un poco de lástima.

-No... ¿Qué voy a ser...? Si no pude terminar mis Humanidades”(Baron Biza, 2013, p. 210). 
negación puesto que bien evidencia el autor conocimiento de causa en su artículo Moda, arte y política de lineamientos esenciales de la estética, al menos, kantiana. ${ }^{5}$

Es patente cierto optimismo idealista de cuño hegeliano en el fin de la obra de arte en Baron Biza -principalmente si se considera además de la novela El desierto y su semilla los ensayos sobre la autobiografía como también la ponencia acerca de la actitud lírica en los tiempos del mercado-. Dicho optimismo es tal que lo lleva a considerar a la producción artística como una instancia reconciliatoria, siendo la obra un vehículo en donde se manifiesta lo divino: culminando su breve ensayo La autobiografía, nos dice que el autobiógrafo llega, gracias a su producción, a lo colectivo, a "esa gran concepción del ser humano que es Dios" (Baron Biza,2010, p. 145); congruentemente con lo anterior en el ensayo La loca no se rinde el autor insiste con el elemento "unificador" de la obra artística cuyo tema es "el amor, la muerte, lo divino" (Baron Biza, 2010, p. 193, la cursiva es mía); también en el mismo ensayo sostiene que lo lírico se presenta "como uno de los senderos existenciales unificadores del ser" (Baron Biza, 2010, p. 191), tal como lo es la religiosidad -tengamos en mente que de manera semejante, para Hegel, tanto arte como religión son diferentes formas de expresar la Idea, es decir, el espíritu, lo divino-.

En un sentido hegeliano la finalidad de la obra de arte es la de manifestar el espíritu absoluto de una manera sensible a través de la materia característica de cada disciplina artística -en este caso, la palabra narrativa, una de las más perfectas de las artes puesto que la materia allí es, se puede decir, etérea, en tanto se ha liberado del propio peso de las cosas extensas-. El arte verdadero, sostiene Hegel, es "un modo de hacer consciente y de expresar lo divino" (Hegel, 2007, p. 11), y luego agrega, al referirse a la forma, que "la apariencia del arte apunta desde sí a algo espiritual" (Hegel, 2007, p. 12).

Se sospecha aquí, entonces, la presencia en la obra de Baron Biza del pensamiento idealista moderno en la confianza en la obra de arte como vehículo del espíritu, otra vez, de la totalidad; un acceso imposible, vale decir, en la pragmática sociedad capitalista industrial que, con su razón instrumental, tiende a fragmentar nuestra unidad -tal como indica en La loca no se rinde-. Se entrevé en el autor un optimismo idealista en el poder de la obra artística, y es al menos en ella en donde Baron Biza deposita sus esperanzas. La cifra de su anhelo se puede señalar ya en Hegel, quien afirma "que el arte está llamado a desvelar la verdad en forma de configuración artística sensible, a representar aquella oposición reconciliada, y tiene por tanto su fin último en sí, en esta representación y este desvelamiento mismos" (Hegel, 2007, p. 44). Con respecto a esto debe recordarse que es en la elaboración de una producción artística de carácter autobiográfica en la que Baron Biza aspira a poder reconstruir su historia personal, y a través de ella lograr aquella tan mentada reconciliación.

5. Baron Biza, refiriéndose al arte autónomo nacido en la modernidad, menciona que "Kant le asignaba a la obra de arte una característica de 'inútil', al margen de la especulación comercial o de toda índole”(2010, p.188). En este sentido, para Kant, la característica de la expresión estética es que esta sea una finalidad sin fin, que carezca por completo de utilidad alguna. Cf. Kant, "Analítica de lo bello" incluido en Crítica del juicio (2007/1790).

6. Hay que tener en consideración la relación de este concepto con el de reconciliación y el de síntesis. De tal manera para Baron Biza lo lírico, el núcleo de la lírica, la actitud lírica, o el concepto de artisticidad de Gottfried Benn utilizado como expresión sinonímica por nuestro autor en La autobiografía, no es sino uno de los caminos existenciales que unifican el ser, de manera conjunta con la religiosidad (Baron Biza, 2010, p. 195). 
Sin embargo, también en su significativa ponencia La loca no se rinde, que fue incluida con algunas modificaciones en la novela, reconoce que en las actuales condiciones de existencia material se hace difícil dicha reconciliación, por lo que Baron Biza acaba resignándose, entendiendo por tanto el proceso como una especie de dialéctica sempiterna en el mejor de los casos, cuando no mocha. Es decir, el montaje dialéctico de diversas instancias de la vida del autor, a las que son incorporados fragmentos de las novelas paternas y demás pasajes de la historia personal, persigue una reconciliación que se sabe no podrá ser alcanzada; pero que al menos se pone en marcha en la novela en la búsqueda reconstructiva de ese pasado personal y tras un cierto anhelo redentorio: "el auténtico autobiógrafo no debe escribir para elogiarse ni para chismear, sino para salvarse de la muerte. ¿Cómo trata de salvarse? Escribiendo” (Baron Biza, 2010, p. 144).

Toda la formación temprana del autor, de la que se da cuenta en la obra al recordar sus primeros estudios en distinguidos colegios, y la instrucción en artes clásicas que en ellos recibió (formación que probablemente haya sido la que definió al crítico de artes plásticas que Baron Biza acabó siendo), fue puesta en suspenso a la hora de enfrentar la devastación que el ácido produjo en el rostro materno. La belleza de aquel rostro entró en decadencia a la par que las concepciones acerca de lo bello en el hijo. En la perspectiva decadentista la naturaleza perdió los consabidos atributos de bondad y belleza, y viene a presentarse, como el rostro de la madre, en un desolado cuadro de viscosidad y hastío.

En una charla de café con un personaje identificado como "un licenciado" (Baron Biza, 2013, p. 207) interesado en la obra del padre, aquel le comenta que Arón Gageac -nombre que Baron Biza le asigna a su progenitor en la novela- ya al final de su vida se había transformado en un "autor convertido en emisor de resentimiento y provocación contra todo ideal que camina. Es el fracaso de los grandes discursos y de la razón universal del Iluminismo" (Baron Biza, 2013, p. 210). La inclusión de una anécdota semejante no es menor, ya que señala el punto de partida del mismo escritor, esto es, tras adquirir las herramientas interpretativas propias de la cultura clásica y de las artes figurativas, dicha percepción fue trastocada con el atentado perpetrado por el padre. La desfiguración del rostro materno puede corresponderse con el derrumbe de todo optimismo idealista, con el reconocimiento del fracaso de los grandes discursos y de la razón ilustrada; así el autor autobiógrafo al mismo tiempo que comprendía la declinación de la racionalidad decimonónica, la decadencia de los sistemas filosóficos, experimentaba en concordancia con ello la degradación de la carne gracias a la acción del ácido: tras la agresión la "cara ingenuamente sensual de Eligia empezó a despedirse de sus formas y colores" (Baron Biza, 2013, p. 21), y luego el autor agrega que el rostro de la madre

había sido el lugar en que con más evidencia se manifestaron su historia, la sangre de los Presotto -pobres inmigrantes italianos- y su fe empecinada en la razón y la voluntad de saber. Pero los 'siempres' de su cara se estaban esfumando. (Baron Biza, 2013, p. 23, la cursiva es mía)

Nótese incluso en esta última cita que la degradación iniciada en la cara se identifica también con la pérdida de una identidad que se caracterizaba por una empecinada fe en la razón y en el conocimiento. Esta relación no es azarosa, sino que en ella puede cifrarse la autoconciencia de una transformación hermenéutica: la certeza de la pérdida de la certeza ilustrada. 
Así entonces la escritura autobiográfica que propone Baron Biza en su ponencia del 2001 debe suponer que el autor no puede pretender arrogarse un conocimiento total respecto de sí mismo, sino que en cambio sabe "que gran parte de lo que escribe no se comprende, que él no se presenta como un proyecto cerrado, como un ser que se ha reconocido a sí mismo totalmente" (Baron Biza, 2010, p. 144 y ss.). De tal manera registra las fallas de las pretensiones de la autobiografía decimonónica, en tanto que en ella la figura del escritor es la de un individuo que se autoconoce a la perfección, por el contrario, sostiene que "cuando la gente habla sobre sí misma, habitualmente es cuando más se equivoca" (Baron Biza, 2010, p. 142), y que precisamente es en dicho género narrativo en donde el escritor lleva adelante su trabajo tras la búsqueda de salvarse de la muerte por medio de la escritura.

Con respecto a la variación de la ponencia acerca de la dificultad de la lírica presentada en el contenido del capítulo XI de El desierto y su semilla, se encuentra en ella un pasaje donde refiere que "El núcleo de lo lírico permanece ajeno al tiempo y la contradicción. Desde su excentricidad, destruye la lógica, la gramática, las racionalidades, puesto que en su carácter de actualización primaria no se rinde nunca a las sistematizaciones" (Baron Biza, 2013, p. 213). Puede observarse entonces aquí que Baron Biza reconoce la incapacidad de todo abordaje sistemático de la obra lírica, al tiempo que comprende que la misma elude toda constricción lógica-racional, ubicándose más allá de esta, sin importar incluso investirse de un carácter contradictorio. Este elemento puede ayudar a repensar aquello que venimos esbozando: en Baron Biza emergen, por un lado, un cierto anhelo -e incluso esperanza- idealista al considerar la obra como una instancia purgativa, como el momento de cierta reconciliación y superación del drama familiar (en donde como soporte de dicha perspectiva se entrevé un claro andamiaje de estética hegeliana); mientras que por el otro persiste el reconocimiento mismo de la limitación de todo sistema de pensamiento - un ejemplo de ello es la imposibilidad de captar la lírica-, y con dicha posición despuntan ciertas actitudes decadentistas.

\section{3.}

Siendo consciente de la imposibilidad de esbozar la totalidad del drama familiar a través de una novela, Baron Biza recurre a los restos para componer su obra. Son las ruinas, los vestigios, los que habilitan una narración que ambiciona alcanzar la identidad, pero que nunca termina de saldarse.

Apela nuestro autor a una dialéctica que procura la reconciliación, aunque es sin embargo consciente de que ella solo es dable en un estadio aún inalcanzable, por lo que acaba quedando es la incesante contraposición de instancias, siendo la novela, en tanto producción artística cerrada, el resultado de tales contraposiciones.

En su ensayo sobre la autobiografía reconoce que hay un conocimiento acerca de nosotros mismos que permanece oculto, enterrado si recurrimos a la metáfora de Paul de Man, y como tal es algo informe, que no se puede expresar de un modo sencillo y que no se corresponde con la lógica temporal. Puede observarse entonces que esta posición es sostenida en la diagramación misma de la novela, ya que, como se mencionó anteriormente, entresaca diversos sucesos de la experiencia vital para plasmarlos, mediación incluida, en los capítulos. 
Jorge Baron Biza reconoce que en la escritura autobiográfica el escritor no puede colocar los hechos tal como ocurren o se suceden, sino que entre lo vivenciado y lo escrito hay una mediación. Como dijera el autor en su artículo La autobiografía: "la vida no es un torrente que cae sobre un papel y queda ahí plasmada” (Baron Biza, 2010, p. 142). Estos supuestos sugieren una concepción del tiempo histórico en un sentido no meramente cronológico y continuo al momento de la escritura autobiográfica, puesto que el escritor es incapaz de reproducir toda la secuencia de experiencia vital; en su lugar se erige la noción de una relación con la historia -en este caso personal- que bien le cabe la figura de un salto dialéctico, esto es, desde el ahora del momento de la escritura se da un salto al pasado, al terreno de lo vivenciado, del cual es extraído un suceso y reinterpretado en el instante de la escritura. Esa distancia que separa lo acontecido de lo reconsiderado no se presenta bajo una secuencia lógica-causal, sino que median entre ellos multitudes de instantes que no son incorporados a la obra, sino simplemente desechados.

Baron Biza (2010) reconoce, con respecto a la autobiografía, que lo temporal -esto es, el continuo temporal- es lo que nos ordena, pero que no son sino los contenidos del subconsciente o del mundo de nuestros sueños los que no solo escapan a toda lógica temporal, sino que incluso tienden a subvertirla (aquello que irrumpe desde el fondo). Lo que se da fuera del tiempo es incomprensible, y constituye a los ojos de nuestro autor la esencia misma de la espiritualidad.

Teniendo en consideración el trabajo de Paul de Man, La autobiografía como desfiguración (1991), si bien el texto autobiográfico se produce en el mundo del sol, esto es en el ámbito de lo consciente, lo escrito viene impregnado de aquel profundo universo contradictorio que se presenta en el acto de rememoración, y que manifiesta un instante pasado con un fulgor metarracional que es por completo ineludible. En este sentido, Baron Biza declara que la obra se presenta como una "metarracionalidad autosuficiente" que se resiste a ser envuelta por la irracionalidades de la racionalidad ilustrada -ilustrada digo yo aquí, Baron Biza profiere “irracionalidades de la razón ideológica” (2010, p. 197)-.

En relación a lo anterior debe recordarse que Baron Biza, en su referencia a Goethe, menciona que su poesía lírica no era sino producto de la plenitud de un instante en el que se suspende toda racionalidad, voluntad y conocimiento utilitario.

En el ensayo sobre la autobiografía se refiere a dicho género como "un elemento integrador del ser humano" (Baron Biza, 2010, p. 144), puesto que el escritor trata de salvarse de la muerte escribiendo, aunque sepa o reconozca que "gran parte de lo que escribe no se comprende, que él no se presenta como un proyecto cerrado, como un ser que se ha conocido a sí mismo totalmente" (Baron Biza, 2010, p. 145); y esto lo sabe porque, precisamente, es consciente de la imposibilidad de esbozar la totalidad, tal como se expuso en el punto anterior -sabe bien Baron Biza aquello que afirmaba Paul de Man, esto es, que "la autobiografía desposee y desfigura en la misma medida que restaura" (De Man, 1991, p. 118)-.

Cobra entonces importancia la idea de la obra como sumatoria de fragmentos, que podemos aventurar a identificarlos con vivencias, en donde el autor elabora entonces una obra compuesta de porciones que en un juego dialéctico anhelan una reconciliación eternamente postergada, y es por ello que uno puede aventurarse a definir la escritura de Jorge Baron Biza como decadente, en 
tanto consciente de esa declinación, de esa imposibilidad. Sigo aquí a Ernest Curtius, para quien el decadentismo es "la obsesión por todos los síntomas de una vida que desciende a su ocaso" (1989, p. 297). Para este, el decadente se siente atraído por el decaimiento, lo acepta y lo goza en estéril voluptuosidad, y pese a que el sentimiento de ruina lo haga sufrir, lo que experimenta es una "seducción por al abismo" (1989, p. 297).

Juan Bautista Ritvo indica que con el decadentismo se ingresa en "una nueva época en lo que respecta a la concepción de la obra, tan distinta en este nivel del clasicismo y del neoclasicismo: la obra se define por la imposibilidad de la obra" (2006, p. 189). Así la reconstrucción de una vida en la producción estética no puede alcanzar la totalidad puesto que la esterilidad no es sino uno de los caracteres invariantes del decadentismo, (cf. "El decadentismo francés” en Ritvo, 2006). La novela de Baron Biza está compuesta de injertos, de vivencias -i.e., de "recuerdos en los que predomina más la sensación y la emoción que la simple memoria automática” (Baron Biza, 2010, p. 141), tal como argumenta en su programático texto referido al género que practica-, de fragmentos (como los de las novelas del padre en la del hijo). Con ello se refuerza la idea de la obra como un montaje de injertos al ser presentados sus capítulos despojados de toda intriga, de toda épica, de todo desarrollo y finalidad.

En suma, El desierto y su semilla se revela como un montaje de injertos, en donde podemos pensar cada fragmento como un suceso pretérito, cerrado como una mónada, que en juego con los otros promueve un movimiento dialéctico que, aunque pretenda, sabe que no podrá arribar a síntesis alguna, y que se conforma con el movimiento mismo puesto que al menos en su estéril búsqueda se va reconstruyendo algo de lo que trágicamente se desmoronó (la vida familiar, el rostro de la madre).

\section{4.}

Detalles estetizantes de la corrosión también señalan un espíritu decadentista: una retórica del esplendor de la ruina, de la descomposición de la forma. Otorga Baron Biza a sus lectores la narración retrospectiva de los pormenores de la declinación de la materia, un rostro que va perdiéndose en la indistinción, y todo ello proferido por un observador distante, acostumbrado al horror, ya hastiado. E1 autor logra rememorar el mutilado rostro materno a través de una descripción tan objetiva como la glosa de cualquier producción de arte visual, en donde el objeto degradado, evidentemente horrendo, se presenta como ambiguamente bello.

Sigo aquí a Juan Ritvo, para quien el decadentismo "es el testigo de una desaparición: desaparece el objeto tras la superficie de la forma que acaba de romperse y los nombres de que se disponía han perdido su alteridad y su mismidad: son huecos, obsoletos" (2006, p. 241). Debe recordarse que anteriormente se había identificado el drama familiar, el atentado sobre la madre, como el índice del resquebrajamiento del idealismo clásico en el autor, de las pretensiones de la razón ilustrada, para habilitar así un claro perfil decadentista. Es que precisamente fue el decadentismo, en tanto movimiento histórico, el que reconoció las limitaciones de los anhelos totalizadores. $Y$ es en el juego de dichas tradiciones que el autor aborda el rostro materno desde la perspectiva de la belleza clásica; y desde allí sostengo: hay algo de aquella búsqueda por la superación de las oposiciones, algo de la tan mentada reconciliación. 
La novela autobiográfica de Baron Biza parece procurarse por medio de la escritura un tipo de purga, y así se comprende que su naturaleza sea catártica, una especie de purificación de la pesada historia familiar por medio de la escritura. Entonces su esperanza conciliatoria, de estéril consecución, opera conjuntamente con un decadentismo que al menos procura una "sublimación de la decadencia" (Ritvo, 2006, p. 183), la de su mayorazgo.

\section{Referencias bibliográficas}

Avaro, N. (2013). Prólogo. En: Baron Biza, J. El desierto y su semilla (pp. 7-16). Ciudad Autónoma de Buenos Aires, Eterna Cadencia.

Baron Biza, J. (2010). Por dentro todo está permitido. Ciudad Autónoma de Buenos Aires, Caja Negra. Baron Biza, J. (2013). El desierto y su semilla. Ciudad Autónoma de Buenos Aires, Eterna Cadencia. Curtius, E. (1989). Ensayos críticos acerca de la literatura europea (E. Valentí, trad.). Madrid, Visor. De Man, P. (1991). La autobiografía como desfiguración. Suplemento Anthropos, 29, 113-118. Hegel, G. W. F. (2007). Lecciones sobre la estética (A. Brotons Muñoz, trad.). Madrid, Akal. Kant, I. (2007). Crítica del juicio (M. García Morente, trad.). Madrid, Espasa Calpe (original de 1790). Leibniz, G. (1984). Monadología (M. Fuentes Benot, trad.). Ciudad Autónoma de Buenos Aires, Hyspamérica.

Ritvo, J. B. (2006). Decadentismo y melancolía. Córdoba, Alción.

* Francisco Tanzi es Licenciado en Filosofía (Universidad Nacional de Rosario). Es miembro del Centro de Estudios del Pensamiento Argentino (CEPA) dependiente la Facultad de Humanidades y Artes (UNR). Trabaja como profesor en institutos superiores de formación docente. Sus temas de investigación vinculan las formas del ensayo en América Latina, una estética derivada de la escuela de Frankfurt y ciertos presupuestos de una filosofía de la historia negativa. Actualmente, está escribiendo su tesis de maestría dedicada a la ensayística de Héctor Álvarez Murena.

RECEPCIÓN: 02/12/2019

ACEPTACIÓN: 03/06/2020 